\title{
Alcohol-induced headaches: Evidence for a central mechanism?
}

\author{
Alessandro Panconesi \\ Department of Neurology, Headache Center, San Giuseppe Hospital, Empoli, Fl, Italy
}

\begin{abstract}
Alcoholic drinks (ADs) have been reported as a migraine trigger in about one-third of the migraine patients in retrospective studies. Some studies found that ADs trigger also other primary headaches. The studies concerning the role of ADs in triggering various types of primary headaches published after the International Headache Society classification criteria of 1988 were reviewed, and the pathophysiological mechanisms were discussed. Many studies show that ADs are a trigger of migraine without aura (MO), migraine with aura (MA), cluster headache $(\mathrm{CH})$, and tension-type headache (TH). While data on $\mathrm{MO}$ and $\mathrm{CH}$ are well delineated, those in MA and TH are discordant. There are sparse reports that ADs are also triggers of less frequent types of primary headache such as familial hemiplegic migraine, hemicrania continua, and paroxysmal hemicrania. However, in some countries, the occurrence of alcohol as headache trigger is negligible, perhaps determined by alcohol habits. The frequency estimates vary widely based on the study approach and population. In fact, prospective studies report a limited importance of ADs as migraine trigger. If ADs are capable of triggering practically all primary headaches, they should act at a common pathogenetic level. The mechanisms of alcohol-provoking headache were discussed in relationship to the principal pathogenetic theories of primary headaches. The conclusion was that vasodilatation is hardly compatible with ADs trigger activity of all primary headaches and a common pathogenetic mechanism at cortical, or more likely at subcortical/brainstem, level is more plausible.
\end{abstract}

Key words: Alcohol, headache, migraine, migraine pathogenesis, trigger

\section{Introduction}

Many foods are considered capable of triggering migraine attack, but the relationship is frequently equivocal. ${ }^{[1]}$ Perhaps, only alcohol has what is to be considered a sure dietary trigger, but its importance is still debated. Many retrospective studies show that alcoholic drinks (ADs) act as migraine triggers, at least occasionally, in about one-third of migraine patients, and as frequent/consistent trigger in about $10 \%$ of patients. ${ }^{[2]}$ Some studies report that ADs are also a trigger of tension-type headache (TH). ${ }^{[1]}$

\section{Address for correspondence:}

Dr. Alessandro Panconesi, Via Amedeo Bassi 20,

50025 Montespertoli, FI, Italy.

E-mail: a.panconesi@usl11.toscana.it

\begin{tabular}{|l|l|}
\hline \multicolumn{2}{|c|}{ Access this article online } \\
\hline Quick Response Code: & Website: \\
\hline & www.ruralneuropractice.com \\
\cline { 2 - 3 } & \\
\hline D. & \\
\hline
\end{tabular}

In the International Headache Society (IHS) classification, alcohol-induced headache is included as secondary headaches, in the section "Headache attributed to a substance or its withdrawal." [3] However, problems for the classification of headache triggered by alcohol using IHS criteria were recently discussed. ${ }^{[4]}$ One is the differentiation between hangover headache and migraine attack triggered by alcohol in diagnosed migraine patients. ${ }^{[5-7]}$

Alcohol being a common trigger in the principal types of primary headaches, suggest that these headaches can share a pathogenetic mechanism and that this trigger acts at the start of the neuronal pathway involved in headache provocation. To define this important issue, we have reviewed alcohol as a trigger of primary headaches and discussed the possible correlation of the results

This is an open access article distributed under the terms of the Creative Commons Attribution-NonCommercial-ShareAlike 3.0 License, which allows others to remix, tweak, and build upon the work non-commercially, as long as the author is credited and the new creations are licensed under the identical terms.

For reprints contact: reprints@medknow.com

How to cite this article: Panconesi A. Alcohol-induced headaches: Evidence for a central mechanism? J Neurosci Rural Pract 2016;7:269-75. 
with the principal pathogenetic theories of the primary headaches.

\section{Methods}

This review was performed using a literature search on PubMed from 1988 (date of the first IHS classification) to December 2014. Search terms of "alcohol," "wine," "food trigger," "dietary trigger," "migraine," "headache" were used. Additional sources were identified via manual search of bibliographies, references lists, and previous peer reviews. Review was restricted to studies written in English. Original studies were selected if they reported in the results a numeric percentage of headache patients referring any ADs as a trigger factor. Thirty-five papers were found corresponding to these criteria. Other studies useful for the correlation of the results with the pathogenesis of the primary headaches where also selected.

\section{Results}

\section{Migraine without aura}

A recent review reports that in retrospective studies performed in different countries, about one-third of migraine patients indicate alcohol as a migraine trigger, and all ADs may act as trigger. ${ }^{[2]}$ Fourteen studies reveal a percentage higher than $20 \%$ (mean $31.9 \%$ ) [Table 1]. ${ }^{[8-21]}$ However, some of these studies show that alcohol acts as a trigger at least occasionally in a high percentage, but as a frequent/consistent trigger in only $10 \%$ of patients. ${ }^{[18,19]}$ In other eight studies performed in India, Japan, Turkey, China, and Italy, the percentages of alcohol or wine as migraine without aura (MO) trigger are very low $(0-11 \%) \cdot{ }^{[22-29]}$ In Italy and Turkey, the low percentage was confirmed by many studies. ${ }^{[23,25-28]}$ Prospective studies on alcohol as migraine trigger are few. One prospective study carried out in Austria (the Pamina study), examines a wide spectrum of factors related to migraine through the application of sophisticated statistical analysis, and provides evidence for the limited importance of nutrition (comprising alcoholic beverages) in the precipitation of migraine. ${ }^{[30]} \mathrm{A}$ broad observational general practice study (Spain, France, Italy) reports alcohol as a trigger in $12 \%$ of migraine patients but prospectively only in $4 \%$ of migraine attacks. ${ }^{[31]}$

\section{Migraine with aura}

Six studies report ADs as a trigger of migraine with aura (MA), four of them by the same Danish group [Table 2]. ${ }^{[8,12,17,19,32,33]}$ Four studies report ADs trigger MA attack in a percentage similar to that found in MO
Table 1: Percentage of migraine without aura patients who report alcoholic drinks as a trigger

\begin{tabular}{|c|c|c|}
\hline Author (country, year) & Patients (n) & Percentage \\
\hline$\overline{R a s m u s s e n ~ a n d ~ O l e s e n ~(D K ~ 1992) ~})^{[8] \dagger}$ & 58 & 27 \\
\hline Rasmussen (DK 1993) ${ }^{[9] *}$ & 119 & 20 \\
\hline Scharff et al. (US 1995) $)^{[10] \dagger}$ & 69 & 35 \\
\hline Peatfield (UK 1995) $)^{[11] *}$ & 347 & 30 \\
\hline Russell et al. (DK 1996) ${ }^{[12] \dagger}$ & 222 & 39 \\
\hline Bánk and Márton (HU 2000) $)^{[13]+*}$ & 78 & 30 \\
\hline Spierings et al. (US 2001) $)^{[14]^{*}}$ & 38 & 42 \\
\hline $\begin{array}{l}\text { lerusalimschy and Moreira Filho } \\
(\text { BR 2002) }\end{array}$ & 100 & 28 \\
\hline Henry et al. (FR 2002) ${ }^{[16] *, \dagger, *}$ & 880 & 23 \\
\hline Zivadinov et al. (HR 2003) $)^{[17]+,}$ & 720 & 32 \\
\hline Wöber et al. (AT 2006) ${ }^{[18]+, ;}$ & 66 & 50 \\
\hline Kelman (US 2007) $)^{[19]^{*, \dagger,+}}$ & 1750 & 37 \\
\hline Fukui et al. (BR 2008) $)^{[20] *}$ & 200 & 34 \\
\hline Andress-Rothrock et al. (US 2010) ${ }^{[21] *}$ & 200 & 20 \\
\hline Takeshima et al. (JP 2004) ${ }^{[22] \dagger}$ & 213 & 1 \\
\hline Karli et al. (TR 2005) $)^{[23] \dagger}$ & 33 & 6 \\
\hline Yadav et al. (IN 2010) $)^{[24] \dagger}$ & 182 & 0 \\
\hline Finocchi and Sivori (IT 2012) $)^{[25] \dagger}$ & 100 & 4 \\
\hline Mollaoglu (TR 2013) $)^{[26],+,}$ & 126 & 3 \\
\hline Panconesi et al. (IT 2013) $)^{[27] *, \dagger, \$}$ & 401 & 5 \\
\hline Baldacci et al. (IT 2013) $)^{[28]+*}$ & 120 & 5 \\
\hline Wang et al. $(\mathrm{CN} 2013)^{[29] *}$ & 394 & 11 \\
\hline
\end{tabular}

${ }^{*}$ Migraine, ${ }^{\circledR} \mathrm{MO},{ }^{\star} \mathrm{MA}$. MO: Migraine without aura, MA: Migraine with aura

Table 2: Percentage of migraine with aura patients who report alcoholic drinks as a trigger. Comparison with migraine without aura

\begin{tabular}{|c|c|c|c|}
\hline Author (country, year) & $\begin{array}{c}\text { MA/MO } \\
\text { patients }(n)\end{array}$ & MA \% & MO \% \\
\hline Rasmussen and Olesen (DK 1992) ${ }^{[8]}$ & $38 / 58$ & 7 & 27 \\
\hline Russell et al. (DK 1996) $)^{[12]^{*}}$ & $111 / 222$ & 27 & 39 \\
\hline Ulrich et al. $(\text { DK 2000) })^{[32] \dagger}$ & 169 & 9 & \\
\hline Zivadinov et al. (HR 2003) $)^{[17] *}$ & $258 / 462$ & 35 & 30 \\
\hline Kelman (US 2007) ${ }^{[19] \S}$ & $419 / 855$ & $>\mathrm{MO}$ & 37 \\
\hline Hauge et al. (DK 2010) ${ }^{[33] !}$ & 347 & 30 & \\
\hline
\end{tabular}

${ }^{*} 4 \%$ coexisting with $\mathrm{MO},{ }^{\dagger} 7 \%$ coexisting with $\mathrm{MO},{ }^{\circledR} 7 \%$ coexisting with $\mathrm{MO},{ }^{\S} \mathrm{No}$ specification if MA coexists with $\mathrm{MO}$ in some patients, $140 \%$ coexisting with $\mathrm{MO}$. MO: Migraine without aura, MA: Migraine with aura

patients (about $30 \%$ ). In these studies, MA coexists with $\mathrm{MO}$ in a variable percentage of patients or this was not specified..$^{[12,17,19,33]}$ Two studies report a much lesser percentage $(<10 \%))^{[8,32]}$ Other studies, carried out in Japan, Turkey, and Italy, find that ADs never precipitated MA, but these studies also report that ADs rarely precipitate $\mathrm{MO}$ and $\mathrm{TH} .{ }^{[22,23,27]}$

A recent detailed study shows a high number of factors that triggered MA attack, and more importantly, a high number of factors that frequently precipitated MA attack. ${ }^{[33]}$ In this study, about $30 \%$ of patients with current MA (at least one attack within the last year) report ADs as a trigger, and only about $10 \%$ indicate ADs to trigger often or always an attack. For patients 
having both current $\mathrm{MA}$ and $\mathrm{MO}$ attacks, $\mathrm{ADs}$ are reported as a trigger of $\mathrm{MO}$ in $51 \%$ of patients and of MA in $40 \%$ of MA patients. In a further evaluation of patients indicating at least one trigger factor where exposure often or always triggers an attack of MA, $17 \%$ of them report ADs as a trigger: In $90 \%$ of these cases, ADs cause only $0-25 \%$ of their MA attacks while in the other $10 \%$ of cases, $26-50 \%$ of attacks. ${ }^{[34]}$ All ADs trigger MA attacks, in $80 \%$ of cases within $3 \mathrm{~h}$, and consistent with other studies, red wine is frequently indicated..$^{[12,17]}$ A prospective study shows that white wine, red wine, beer, and spirits do not influence the risk of MA, similarly to $\mathrm{MO}$ or headache, while sparkling wine increases the risk of MA. ${ }^{[35]}$

\section{Tension-type headache}

Five studies report $\mathrm{ADs}$ as $\mathrm{TH}$ trigger in approximately the same percentage $(30 \%)$ of MO patients [Table 3]. ${ }^{[9,10,14,17,18]}$ However, the most extensive study also includes $\mathrm{TH}$ patients with coexisting migrainous headaches. ${ }^{[17]}$ Peatfield find that $21 \%$ of $\mathrm{TH}$ with migraine features, but only $2 \%$ of pure $\mathrm{TH}$, report sensitivity to ADs while Ulrich states that ADs provoke $\mathrm{TH}$ in MA and MO patients but not in TH patients. ${ }^{[11,36]}$ In these two studies, red wine is the most common ADs involved in triggering TH attacks, in accordance with another study ${ }^{[18]}$ Other studies find that $\mathrm{ADs}$ rarely precipitated both migraine and TH. ${ }^{[22,23,27,29]}$ Furthermore, an old prospective study reports that $\mathrm{ADs}$ trigger vascular headaches but not $\mathrm{TH}^{[37]}$

\section{Cluster headache}

More than $50 \%$ of patients indicate ADs are triggers of cluster headache $(\mathrm{CH})$ attacks in chronic $\mathrm{CH}$ and in episodic $\mathrm{CH}$ only during bouts [Table 4]. ${ }^{\left[{ }^{[38-45]}\right.}$ Studies in Asiatic population, similarly to an older study on Italian population, show a smaller percentage of $\mathrm{CH}$ patients reporting ADs as a trigger, which may be due in part to different alcohol habits. ${ }^{[46-49]}$ This great variability appears even considering only $\mathrm{CH}$ patients who consume alcohol. ${ }^{[39,46,47]}$

One study shows that ADs trigger $\mathrm{CH}$ attack within $2 \mathrm{~h}$ in $82 \%$ of cases, red wine being the most implicated. ${ }^{[40]}$ However, others report beer as the most common trigger. ${ }^{[43]}$ Curiously, several reports show transitory remission as a result of alcohol consumption and also delay of the following attack through consumption of large amounts of alcohol. ${ }^{[00,45]}$ Almost $50 \%$ of $\mathrm{CH}$ patients stated they drank alcohol. ${ }^{[40,41,43,47]}$ Some reports suggest increased alcohol consumption, and even alcohol abuse, in $\mathrm{CH}$ population. ${ }^{[50,51]}$ Other studies do not support this, finding almost $50 \%$ change drinking habits, avoiding alcohol. ${ }^{[52,53]}$ In fact, $\mathrm{CH}$
Table 3: Percentage of tension-type headache patients who report alcoholic drinks as a trigger. Comparison with migraine patients

\begin{tabular}{|c|c|c|c|}
\hline Author, (country, year) & $\begin{array}{c}\text { TH/M } \\
\text { patients }(n)\end{array}$ & TH \% & M \% \\
\hline Rasmussen and Olesen (DK 1993) ${ }^{[9] *}$ & $167 / 119$ & 27 & 20 \\
\hline Scharff (US 1995) $)^{[10]}$ & $52 / 69$ & 31 & 35 \\
\hline Peatfield (UK 1995) ${ }^{[11]}$ & $40 / 347$ & 2 & 30 \\
\hline Ulrich et al. (DK 1996) ${ }^{[36]}$ & 44 & 0 & \\
\hline Spierings et al. (US 2001) $)^{[14] *}$ & $17 / 38$ & 29 & 42 \\
\hline Zivadinov et al. (HR 2003) ${ }^{[17]+,}$ & $1319 / 720$ & 30 & 32 \\
\hline Takeshima et al. (JP 2004) $)^{[22] \dagger, *}$ & $412 / 213$ & 1 & 1 \\
\hline Karli et al. (TR 2005) ${ }^{[23]}$ & $31 / 33$ & 6 & 6 \\
\hline Wöber et al. (AT 2006) ${ }^{[18] *}$ & $22 / 66$ & 30 & 50 \\
\hline Wang et al. (CN 2013) ${ }^{[29]}$ & $344 / 720$ & 7 & 11 \\
\hline Panconesi et al. (I 2013) ${ }^{[27]}$ & $47 / 401$ & 0 & 5 \\
\hline
\end{tabular}

Table 4: Percentage of episodic cluster headache and chronic cluster headache patients who report alcoholic drinks as a trigger

\begin{tabular}{|c|c|c|}
\hline Author (country, year) & Patients (n) & Percentage \\
\hline Levi et al. (SE 1992) ${ }^{[38]}$ & 49 & $79(\mathrm{ECH})$ \\
\hline Bahra et al. (UK 2002) $)^{[39]}$ & 230 & 63 (65 ECH, $54 \mathrm{CCH})$ \\
\hline Schürks et al. (DE 2006) ${ }^{[40]}$ & 257 & 53 (51 ECH, $58 \mathrm{CCH})$ \\
\hline Donnet et al. (FR 2007) ${ }^{[41]}$ & 113 & $31(\mathrm{CCH})$ \\
\hline Rainero et al. (IT 2010) $)^{[42]}$ & 110 & $44(\mathrm{ECH}+\mathrm{CCH})$ \\
\hline Rozen and Fishman (US 2012) ${ }^{[43]}$ & 1134 & $52(\mathrm{ECH}+\mathrm{CCH})$ \\
\hline Lin et al. (TW 2004) ${ }^{[46]}$ & 104 & $19(\mathrm{ECH})$ \\
\hline Dong et al. (CN 2013) ${ }^{[47]}$ & 120 & $27(\mathrm{ECH}+\mathrm{CCH})$ \\
\hline Xie et al. (CN 2013) $)^{[48]}$ & 26 & $38(\mathrm{ECH})$ \\
\hline
\end{tabular}

$\mathrm{ECH}$ : Episodic cluster headache, $\mathrm{CCH}$ : Chronic cluster headache

patients reduce alcohol consumption during cluster period. ${ }^{[38,43,51]}$

\section{Other primary headaches}

A recent Danish study reports that familial hemiplegic migraine (FHM) share environmental migraine triggers with $\mathrm{MA}$ and $\mathrm{MO}$, including ADs in $15 \%$ of patients. ${ }^{[54]}$ Hemicrania continua is exacerbated by alcohol within $3 \mathrm{~h}$ (38\% of patients). ${ }^{[55]}$ Of the other trigeminal autonomic cephalalgias (TACs), paroxysmal hemicrania is reported to be triggered by alcohol while there are no reports for short-lasting unilateral neuralgiform headache. ${ }^{[56]}$

\section{Discussion}

Many of retrospective studies report that ADs trigger migraine attack in about one-third of $\mathrm{MO}$ population. A higher percentage of patients (over $50 \%$ ) referring ADs as a trigger is found in $\mathrm{CH}$. The role of alcohol in other types of primary headaches is less uniformly defined. The more detailed study shows that ADs are a trigger 
of MA attack in a similar percentage to MO attack, ${ }^{[33]}$ confirming the data of earlier studies, ${ }^{[12,17,19]}$ but not the low percentage found in previous studies of the same Danish group. ${ }^{[8,32]}$ The same Danish group reports that the typical triggers of FHM are the same of MA, including ADs. ${ }^{[54]}$ The role of alcohol in TH is less surely defined. While many studies show that ADs trigger headache in $\mathrm{TH}$ patients in approximately the same percentage $(30 \%)$ as in migraine patients, other studies show that ADs trigger $\mathrm{TH}$ in migraine patients ${ }^{[36]}$ but not in patients with pure TH. ${ }^{[11,27]}$ Moreover, the larger study also includes $\mathrm{TH}$ patients with coexisting migrainous headaches. ${ }^{[17]}$ This wide variability may results from the similar phenotypic features between $\mathrm{MO}$ and $\mathrm{TH}$ while $\mathrm{MA}$ and $\mathrm{CH}$ have more distinctive characteristics. ${ }^{\left[{ }^{[3]}\right.} \mathrm{ADs}$ have been reported to trigger even more rare forms of primary headaches such as FHM, hemicrania continua, and paroxysmal hemicranias. ${ }^{[54-56]}$

The interval between ADs intake and the start of MO is not well determined in many studies. However, it is reported that in $80 \%$ of cases, ADs can trigger MA attacks and $\mathrm{CH}$ attacks within 3 and $2 \mathrm{~h}$, respectively; consistent with other studies, ${ }^{[12,17]}$ red wine is the principal alcohol trigger. ${ }^{[34,40]}$ Even MO induced experimentally by red wine developed for the most part within $3 h .{ }^{[57]}$ However, all ADs provoke headache and the type of beverage most frequently consumed in a country will probably be the type of ADs most commonly reported to trigger headache. ${ }^{[2,43]}$

In contrast to the well-defined role of ADs in MO patients found in many studies, in India, Japan, Turkey, China, and Italy, a much lower percentages of MO patients indicate ADs as a trigger, perhaps partly due to alcohol habits, that is to lower consumption or different beverage strength to Europe and US. ${ }^{[22-29]}$ Cultural differences can be responsible even of the very low percentage of $\mathrm{MA}$ and TH patients and of the lower percentage of $\mathrm{CH}$ patients referring $\mathrm{ADs}$ as a trigger found in these countries. ${ }^{[22,23,27,29,46-48]}$ In fact, in comparison to Europe and the US, the percentage of abstainers in India and Turkey is much higher and the alcohol consumption per capita is much lower, but this assumption is not valid for Italy and Japan. Conversely, in Brazil, the percentage of abstainers is high while the percentage of MO patients sensitive to ADs is equal to that found in Europe and US. ${ }^{[58]}$ In addition to the population, the frequency estimates vary widely based on the study approach. Reported rates of trigger factors vary with the method of the study (retrospective vs. prospective, spontaneous report vs. checklists, population vs. clinic based), and many methodological difficulties of investigation was highlighted. ${ }^{[59-62]}$ Differently to retrospective studies, influenced by recall bias, few prospective studies provide evidence for the absence or very limited role of ADs in the precipitation of migraine. ${ }^{[30,31,35]}$

Many population-based studies, carried in various countries show an inverse relationship between alcohol and migraine, both in MO than MA, and nonmigraine headache. ${ }^{[4,63]}$ Recently, two studies show that patients with chronic migraine compared to patients with chronic TH and with patients without headache, less likely drink alcohol. ${ }^{[27,64]}$ A possible explanation for the inverse association between alcohol use and headache disorders is that subjects with headache disorders may be abstaining from alcohol as it is a trigger for their headache attack. In fact, $90 \%$ of MA patients sensitive to ADs report abstaining or avoiding certain type of alcohol and $\mathrm{CH}$ patients reduce alcohol consumption during cluster periods. ${ }^{[34,38,43,51]}$ However, some observations seem not to support the explication that migraine patients consume less ADs because they trigger migraine attacks: (1) Among migraine patients who did not drink alcohol at all (about $50 \%$ ), only 3\% reported that abstaining from alcohol was a result of alcohol as a migraine trigger; ${ }^{[27]}$ (2) differently with we can expect if ADs trigger migraine, an higher use of $\mathrm{ADs}$ was reported in chronic migraine in comparison whit episodic migraine ${ }^{[64]}(3)$ the percentage of subjects who never or seldom consume ADs is higher in migraine and nonmigraine headache ${ }^{[63,65,66]}$ which suggests that factors other than previous experience of alcohol as a trigger can contribute to reduced alcohol consumption in migraine, such as personal preference. ${ }^{[4]}$

\section{The possible triggering site}

However, if ADs are a trigger factor of virtually all primary headaches, a fundamental question emerges: That is if ADs act at different levels in triggering the primary headaches or do they act at an initial level of a common pathogenetic pathway. The second hypothesis is more plausible, because it seems unlikely that ADs may act with different mechanisms in different forms of headaches but with similar phenotypic features.

Meningeal nociceptors activation through inflammatory/ vasodilatatory mechanism is suggested responsible of migraine pain: However, how these nociceptors are activated remains largely speculative. Cortical spreading depression (CSD), a transient neuronal and glial depolarization that propagates slowly across the cerebral cortex, is the putative electrophysiological event underlying migraine aura and has been proposed as the mechanism responsible for the activation of the migraine pain pathway, but many arguments against its role are reported. ${ }^{[67]}$ Whether the pain in $\mathrm{TH}$ originates from myofascial tissues or from central mechanisms in the 
brain is still a matter for debate. However, the present consensus is that peripheral pain mechanisms have a role in episodic TH whereas central dysnociception is predominant in chronic TH. ${ }^{[68]}$ Several studies support the hypothalamic involvement in the TACs pathophysiology ${ }^{[69]}$

Concerning migraine pain, animal studies report that alcohol, mimicking capsaicin, provokes neurogenic inflammation in the trigeminovascular system, and vasodilatation of meningeal vessels through calcitonin gene-related peptide (CGRP) release from perivascular sensory nerve terminals. ${ }^{[70]}$ Many studies with noninvasive imaging techniques has well established that low-moderate doses of alcohol, after oral or intravenous (alcohol clamp) administration, increases cerebral blood flow. The increased cerebral perfusion, due to direct or indirect vasodilatory mechanisms, was found in most cerebral regions, stronger in women, and inversely correlated with sensitivity of alcohol. ${ }^{[71-73]}$ Therefore, alcohol may have an action similar to other strong vasodilators such histamine, CGRP, and glyceryl trinitrate $(\mathrm{GTN})$, which trigger migraine. However, disagreement between cranial vasodilatation and drug-provoked headache suggests that vasodilatation per se could not explain the induced headache. ${ }^{[74-76]}$

If the vasodilator action of alcohol at the trigeminovascular level can theoretically be compatible with $\mathrm{MO}$ and $\mathrm{CH}$ provocation, how can it be the trigger of aura and subsequent migraine pain or TH pain?

Other vasodilating drugs such as CGRP and nitroglycerin/GTN failed to induce migraine-like attacks and aura in patients with FHM, while in a small percentage of patient with MA, they have been reported to provoke aura symptoms associated with migraine-like headache, but a role of experimental stress cannot be excluded. ${ }^{[77-80]}$ On the other hand, there is no description in publications that histamine triggers MA. It is also difficult to sustain a direct vasodilating action of alcohol in the triggering $\mathrm{TH}$ if we do not believe in a pathogenethic mechanism in common between migraine and $\mathrm{TH}$.

Migraine triggers, included ADs, can theoretically provoke CSD which can theoretically be responsible for MA, but also for FHM and MO. But at what level do ADs trigger $\mathrm{CH}$, other TACs and TH? However, ethanol infusion decreases the propagation rate of CSD, indicating a decline of tissue excitability and in the CSD initiation mechanisms. ${ }^{[81]}$ Moreover, acute intake of ethanol acts as a central nervous system depressant and at cortical level, alcohol is reported to reduce cortical excitability or facilitate the activity of cortical inhibitory circuits probably through the increase of gamma-aminobutyric acid neurotransmission. ${ }^{[22,83]}$

Therefore, if ADs are definitely confirmed a common trigger of various primary headaches, some of which with phenotypic overlap, it is more plausible that they act probably at a common central cortical or subcortical levels.

A unitary hypothesis suggests that migraine triggers promote headache by the activation of subcortical distinct neuronal pathways convergent into parasympathetic innervation, which if activated results in meningeal release of vasoactive and algesic mediators capable of activating meningeal nociceptors. ${ }^{[84]}$ Another view sustains that migraine headache can be triggered in absence of nociceptor activation, simply as a consequence of disinhibition of tonic control from antinociceptive system, which may result in abnormal central processing of normal sensory signal, ${ }^{[85,86]}$ a mechanism previously theorized as "functional deafferentation." ${ }^{[87]}$

Another important question, previously discussed, is whether alcohol per se or some components of $\mathrm{AD}$ are responsible of headache provocation. ${ }^{[2,4]}$ However, the analgesic activity of alcohol deserve to be briefly discussed because not easily compatible with headache triggered by ADs. In fact, the anesthetic and analgesic properties of alcohol have been recorded for centuries and alcohol is frequently used as self-medication in pain syndromes. ${ }^{[88,89]}$ Some experiments show that alcohol have analgesic effect in the early hours after their administration, which is the amount of time ADs have been reported to trigger $\mathrm{MO}, \mathrm{MA}$, and $\mathrm{CH}$. In fact, rats that received dural stimulation followed by alcohol showed an initial analgesic effect within the first $2 \mathrm{~h}$ after alcohol ingestion; however, 4-6 h later, their pain sensitivity increased. ${ }^{[90]}$ Similarly, intravenously administered alcohol has an analgesic effect in humans, ${ }^{[91]}$ while hyperalgesia is found in alcohol withdrawal. ${ }^{[92]}$ Interestingly, many experiments with "alcohol clamp," a method of infusing alcohol to achieve and maintain a target breath/blood alcohol level for a prolonged time $(3 \mathrm{~h})$, do not report migraine within the $8 \mathrm{~h}$ of the typical study session in several hundred subjects. ${ }^{[4,91,93,94]}$ Only one study carried out on few subjects reports mild and transient headache as side effect in 17-25\% of Japanese but not Caucasians male subjects. ${ }^{[95]}$ Experiments with this technique in migraine patients should be of much interest.

\section{Conclusion}

ADs have been reported to trigger the principal types of primary headaches. Certainly, ADs, even in small doses, 
trigger headache in some MO patients, but what is debated is the degree, which depend, in part, from the population studied, the country where the study was performed and the study approach. While the results in $\mathrm{MO}$ and $\mathrm{CH}$ are in relative agreement, those in MA and TH are discordant. However, if the role of ADs in triggering MA and TH will be confirmed, a common trigger site should be considered. In this case, a direct action at the vascular system is hardly compatible with TH or MA. More plausible is an action at subcortical pain modulatory circuits, which in some way stimulate the neural generator of $\mathrm{CH}$ (hypothalamus?) and of migraine aura (cortex?, thalamus?).

\section{Financial support and sponsorship \\ Nil.}

\section{Conflicts of interest}

There are no conflicts of interest.

\section{References}

1. Wöber C, Wöber-Bingöl C. Triggers of migraine and tension-type headache. Handb Clin Neurol 2010;97:161-72.

2. Panconesi A. Alcohol and migraine: Trigger factor, consumption, mechanisms. A review. J Headache Pain 2008;9:19-27.

3. Headache Classification Committee of the International Headache Society (IHS). The international classification of headache disorders, $3^{\text {rd }}$ edition (beta version). Cephalalgia 2013;33:629-808.

4. Panconesi A, Bartolozzi ML, Guidi L. Alcohol and migraine: What should we tell patients? Curr Pain Headache Rep 2011;15:177-84.

5. Sjaastad O, Bakketeig LS. Hangover headache: Accompanying symptoms. VAGA study of headache epidemiology. J Headache Pain 2004;5:224-9.

6. Kuster GW, da Silva AL, Aquino CH, Ziviani LF, Domingues RB. Frequency and features of delayed alcohol-induced headache among university students. Headache 2006;46:688-91.

7. Zlotnik Y, Plakht Y, Aven A, Engel Y, Am NB, Ifergane G. Alcohol consumption and hangover patterns among migraine sufferers. $\mathrm{J}$ Neurosci Rural Pract 2014;5:128-34.

8. Rasmussen BK, Olesen J. Migraine with aura and migraine without aura: An epidemiological study. Cephalalgia 1992;12:221-8.

9. Rasmussen BK. Migraine and tension-type headache in a general population: Precipitating factors, female hormones, sleep pattern and relation to lifestyle. Pain 1993;53:65-72.

10. Scharff L, Turk DC, Marcus DA. Triggers of headache episodes and coping responses of headache diagnostic groups. Headache 1995;35:397-403.

11. Peatfield RC. Relationships between food, wine, and beer-precipitated migrainous headaches. Headache 1995;35:355-7.

12. Russell MB, Rasmussen BK, Fenger K, Olesen J. Migraine without aura and migraine with aura are distinct clinical entities: A study of four hundred and eighty-four male and female migraineurs from the general population. Cephalalgia 1996;16:239-45.

13. Bánk J, Márton S. Hungarian migraine epidemiology. Headache 2000;40:164-9.

14. Spierings EL, Ranke AH, Honkoop PC. Precipitating and aggravating factors of migraine versus tension-type headache. Headache 2001;41:554-8.

15. Ierusalimschy R, Moreira Filho PF. Precipitating factors of migraine attacks in patients with migraine without aura. Arq Neuropsiquiatr 2002;60:609-13.

16. Henry P, Auray JP, Gaudin AF, Dartigues JF, Duru G, Lantéri-Minet M, et al. Prevalence and clinical characteristics of migraine in France. Neurology 2002;59:232-7.
17. Zivadinov R, Willheim K, Sepic-Grahovac D, Jurjevic A, Bucuk M, Brnabic-Razmilic O, et al. Migraine and tension-type headache in Croatia: A population-based survey of precipitating factors. Cephalalgia 2003;23:336-43

18. Wöber C, Holzhammer J, Zeitlhofer J, Wessely P, Wöber-Bingöl C. Trigger factors of migraine and tension-type headache: Experience and knowledge of the patients. J Headache Pain 2006;7:188-95.

19. Kelman L. The triggers or precipitants of the acute migraine attack. Cephalalgia 2007;27:394-402.

20. Fukui PT, Gonçalves TR, Strabelli CG, Lucchino NM, Matos FC, Santos JP, et al. Trigger factors in migraine patients. Arq Neuropsiquiatr 2008;66:494-9.

21. Andress-Rothrock D, King W, Rothrock J. An analysis of migraine triggers in a clinic-based population. Headache 2010;50:1366-70.

22. Takeshima T, Ishizaki K, Fukuhara Y, Ijiri T, Kusumi M, Wakutani Y, et al. Population-based door-to-door survey of migraine in Japan: The Daisen study. Headache 2004;44:8-19.

23. Karli N, Zarifoglu M, Calisir N, Akgoz S. Comparison of pre-headache phases and trigger factors of migraine and episodic tension-type headache: Do they share similar clinical pathophysiology? Cephalalgia 2005;25:444-51.

24. Yadav RK, Kalita J, Misra UK. A study of triggers of migraine in India. Pain Med 2010;11:44-7.

25. Finocchi C, Sivori G. Food as trigger and aggravating factor of migraine. Neurol Sci 2012;33 Suppl 1:S77-80.

26. Mollaoglu M. Trigger factors in migraine patients. J Health Psychol 2013;18:984-94.

27. Panconesi A, Franchini M, Bartolozzi ML, Mugnai S, Guidi L. Alcoholic drinks as triggers in primary headaches. Pain Med 2013;14:1254-9.

28. Baldacci F, Vedovello M, Ulivi M, Vergallo A, Poletti M, Borelli P, et al. How aware are migraineurs of their triggers? Headache 2013;53:834-7.

29. Wang J, Huang Q, Li N, Tan G, Chen L, Zhou J. Triggers of migraine and tension-type headache in China: A clinic-based survey. Eur J Neurol 2013;20:689-96.

30. Wöber C, Brannath W, Schmidt K, Kapitan M, Rudel E, Wessely P, et al. Prospective analysis of factors related to migraine attacks: The PAMINA study. Cephalalgia 2007;27:304-14.

31. Leone M, Vila C, McGown C. Influence of trigger factors on the efficacy of almotriptan as early intervention for the treatment of acute migraine in a primary care setting: The START study. Expert Rev Neurother 2010;10:1399-408.

32. Ulrich V, Olesen J, Gervil M, Russell MB. Possible risk factors and precipitants for migraine with aura in discordant twin-pairs: A population-based study. Cephalalgia 2000;20:821-5.

33. Hauge AW, Kirchmann M, Olesen J. Trigger factors in migraine with aura. Cephalalgia 2010;30:346-53.

34. Hauge AW, Kirchmann M, Olesen J. Characterization of consistent triggers of migraine with aura. Cephalalgia 2011;31:416-38.

35. Salhofer-Polanyi S, Frantal S, Brannath W, Seidel S, Wöber-Bingöl Ç, Wöber C; PAMINA Study Group. Prospective analysis of factors related to migraine aura - The PAMINA study. Headache 2012;52:1236-45.

36. Ulrich V, Russell MB, Jensen R, Olesen J. A comparison of tension-type headache in migraineurs and in non-migraineurs: A population-based study. Pain 1996;67:501-6.

37. Pryse-Phillips W. Dietary precipitation of vascular headaches. In: Chandra RK, editor. Food Allergy. St. John's, Newfoundland: Nutrition Research Education Foundation; 1987. p. 237-52.

38. Levi R, Edman GV, Ekbom K, Waldenlind E. Episodic cluster headache. II: High tobacco and alcohol consumption in males. Headache 1992;32:184-7.

39. Bahra A, May A, Goadsby PJ. Cluster headache: A prospective clinical study with diagnostic implications. Neurology 2002;58:354-61.

40. Schürks M, Kurth T, de Jesus J, Jonjic M, Rosskopf D, Diener HC. Cluster headache: Clinical presentation, lifestyle features, and medical treatment. Headache 2006;46:1246-54.

41. Donnet A, Lanteri-Minet M, Guegan-Massardier E, Mick G, Fabre N, Géraud G, et al. Chronic cluster headache: A French clinical descriptive study. J Neurol Neurosurg Psychiatry 2007;78:1354-8.

42. Rainero I, Rubino E, Gallone S, Fenoglio P, Negro E, De Martino P, et al. Cluster headache is associated with the alcohol dehydrogenase 4 (ADH4) gene. Headache 2010;50:92-8.

43. Rozen TD, Fishman RS. Cluster headache in the United States of 
America: Demographics, clinical characteristics, triggers, suicidality, and personal burden. Headache 2012;52:99-113.

44. Schürks M, Diener HC. Cluster headache and lifestyle habits. Curr Pain Headache Rep 2008;12:115-21.

45. Evans RW, Schürks M. Alcohol and cluster headaches. Headache 2009;49:126-9.

46. Lin KH, Wang PJ, Fuh JL, Lu SR, Chung CT, Tsou HK, et al. Cluster headache in the Taiwanese - A clinic-based study. Cephalalgia 2004;24:631-8.

47. Dong Z, Di H, Dai W, Pan M, Li Z, Liang J, et al. Clinical profile of cluster headaches in China - A clinic-based study. J Headache Pain 2013;14:27.

48. Xie Q, Huang Q, Wang J, Li N, Tan G, Zhou J. Clinical features of cluster headache: An outpatient clinic study from China. Pain Med 2013;14:802-7.

49. Manzoni GC, Terzano MG, Bono G, Micieli G, Martucci N, Nappi G. Cluster headache - Clinical findings in 180 patients. Cephalalgia 1983;3:21-30.

50. Manzoni GC. Cluster headache and lifestyle: Remarks on a population of 374 male patients. Cephalalgia 1999;19:88-94.

51. Schürks M, Kurth T, Knorn P, Pageler L, Diener HC. Predictors of hazardous alcohol consumption among patients with cluster headache. Cephalalgia 2006;26:623-7.

52. Sjöstrand C, Russell MB, Ekbom K, Waldenlind E. Familial cluster headache: Demographic patterns in affected and nonaffected. Headache 2010;50:374-82.

53. Jensen RM, Lyngberg A, Jensen RH. Burden of cluster headache. Cephalalgia 2007;27:535-41.

54. Hansen JM, Hauge AW, Ashina M, Olesen J. Trigger factors for familial hemiplegic migraine. Cephalalgia 2011;31:1274-81.

55. Cittadini E, Goadsby PJ. Hemicrania continua: A clinical study of 39 patients with diagnostic implications. Brain 2010;133(Pt 7):1973-86.

56. Cittadini E, Matharu MS, Goadsby PJ. Paroxysmal hemicrania: A prospective clinical study of 31 cases. Brain 2008;131(Pt 4):1142-55.

57. Littlewood JT, Gibb C, Glover V, Sandler M, Davies PT, Rose FC. Red wine as a cause of migraine. Lancet 1988;1:558-9.

58. Global Status Report on Alcohol 2004. World Health Organization; 2004. Available from: http://www.faslink.org/WHO_global_alcohol_status_ report_2004.pdf. [Last accessed on 2015 Mar 14].

59. Pavlovic JM, Buse DC, Sollars CM, Haut S, Lipton RB. Trigger factors and premonitory features of migraine attacks: Summary of studies. Headache 2014;54:1670-9.

60. Hoffmann J, Recober A. Migraine and triggers: Post hoc ergo propter hoc? Curr Pain Headache Rep 2013;17:370.

61. Houle TT, Turner DP. Natural experimentation is a challenging method for identifying headache triggers. Headache 2013;53:636-43.

62. Zebenholzer K, Frantal S, Pablik E, Lieba-Samal D, Salhofer-Polanyi S, Wöber-Bingöl Ç, et al. Reliability of assessing lifestyle and trigger factors in patients with migraine - Findings from the PAMINA study. Eur J Neurol 2016;23:120-6.

63. Le H, Tfelt-Hansen P, Skytthe A, Kyvik KO, Olesen J. Association between migraine, lifestyle and socioeconomic factors: A population-based cross-sectional study. J Headache Pain 2011;12:157-72.

64. Schramm SH, Obermann M, Katsarava Z, Diener HC, Moebus S, Yoon MS. Epidemiological profiles of patients with chronic migraine and chronic tension-type headache. J Headache Pain 2013;14:40.

65. Kurth T, Schurks M, Logroscino G, Buring JE. Migraine frequency and risk of cardiovascular disease in women. Neurology 2009;73:581-8.

66. Domingues RB, Domingues SA. Headache is associated with lower alcohol consumption among medical students. Arq Neuropsiquiatr 2011;69:620-3.

67. Levy D, Strassman AM, Burstein R. A critical view on the role of migraine triggers in the genesis of migraine pain. Headache 2009;49:953-7.

68. Fumal A, Schoenen J. Tension-type headache: Current research and clinical management. Lancet Neurol 2008;7:70-83.

69. Holle D, Katsarava Z, Obermann M. The hypothalamus: Specific or nonspecific role in the pathophysiology of trigeminal autonomic cephalalgias? Curr Pain Headache Rep 2011;15:101-7.

70. Nicoletti P, Trevisani M, Manconi M, Gatti R, De Siena G, Zagli G, et al. Ethanol causes neurogenic vasodilation by TRPV1 activation and CGRP release in the trigeminovascular system of the Guinea pig. Cephalalgia 2008;28:9-17.

71. Gundersen H, van Wageningen H, Grüner R. Alcohol-induced changes in cerebral blood flow and cerebral blood volume in social drinkers. Alcohol Alcohol 2013;48:160-5.

72. Marxen M, Gan G, Schwarz D, Mennigen E, Pilhatsch M, Zimmermann US, et al. Acute effects of alcohol on brain perfusion monitored with arterial spin labeling magnetic resonance imaging in young adults. J Cereb Blood Flow Metab 2014;34:472-9.

73. Strang NM, Claus ED, Ramchandani VA, Graff-Guerrero A, Boileau I, Hendershot CS. Dose-dependent effects of intravenous alcohol administration on cerebral blood flow in young adults. Psychopharmacology (Berl) 2015;232:733-44.

74. Panconesi A, Bartolozzi ML, Guidi L. Migraine pain: Reflections against vasodilatation. J Headache Pain 2009;10:317-25.

75. Ashina M, Tfelt-Hansen P, Dalgaard P, Olesen J. Lack of correlation between vasodilatation and pharmacologically induced immediate headache in healthy subjects. Cephalalgia 2011;31:683-90.

76. Wienecke T, Olesen J, Ashina M. Discrepancy between strong cephalic arterial dilatation and mild headache caused by prostaglandin D2 (PGD2). Cephalalgia 2011;31:65-76.

77. Hansen JM, Thomsen LL, Olesen J, Ashina M. Calcitonin gene-related peptide does not cause migraine attacks in patients with familial hemiplegic migraine. Headache 2011;51:544-53.

78. Afridi SK, Kaube H, Goadsby PJ. Glyceryl trinitrate triggers premonitory symptoms in migraineurs. Pain 2004;110:675-80.

79. Sances G, Tassorelli C, Pucci E, Ghiotto N, Sandrini G, Nappi G. Reliability of the nitroglycerin provocative test in the diagnosis of neurovascular headaches. Cephalalgia 2004;24:110-9.

80. Hansen JM, Hauge AW, Olesen J, Ashina M. Calcitonin gene-related peptide triggers migraine-like attacks in patients with migraine with aura. Cephalalgia 2010;30:1179-86.

81. Sonn J, Mayevsky A. The effect of ethanol on metabolic, hemodynamic and electrical responses to cortical spreading depression. Brain Res 2001;908:174-86.

82. Kähkönen S, Wilenius J, Nikulin VV, Ollikainen M, Ilmoniemi RJ. Alcohol reduces prefrontal cortical excitability in humans: A combined TMS and EEG study. Neuropsychopharmacology 2003;28:747-54.

83. Conte A, Attilia ML, Gilio F, Iacovelli E, Frasca V, Bettolo CM, et al. Acute and chronic effects of ethanol on cortical excitability. Clin Neurophysiol 2008;119:667-74.

84. Burstein R, Jakubowski M. Unitary hypothesis for multiple triggers of the pain and strain of migraine. J Comp Neurol 2005;493:9-14.

85. Goadsby PJ. Recent advances in understanding migraine mechanisms, molecules and therapeutics. Trends Mol Med 2007;13:39-44.

86. Lambert GA, Truong L, Zagami AS. Effect of cortical spreading depression on basal and evoked traffic in the trigeminovascular sensory system. Cephalalgia 2011;31:1439-51.

87. Sicuteri F. Quasi-phantom head pain from functional deafferentation. Clin J Pain 1987;3:63-80.

88. Horn-Hofmann C, Büscher P, Lautenbacher S, Wolstein J. The effect of nonrecurring alcohol administration on pain perception in humans: $A$ systematic review. J Pain Res 2015;8:175-87.

89. Zale EL, Maisto SA, Ditre JW. Interrelations between pain and alcohol: An integrative review. Clin Psychol Rev 2015;37:57-71.

90. Maxwell CR, Spangenberg RJ, Hoek JB, Silberstein SD, Oshinsky ML. Acetate causes alcohol hangover headache in rats. PLoS One 2010;5:e15963.

91. Perrino AC Jr., Ralevski E, Acampora G, Edgecombe J, Limoncelli D, Petrakis IL. Ethanol and pain sensitivity: Effects in healthy subjects using an acute pain paradigm. Alcohol Clin Exp Res 2008;32:952-8.

92. Gatch MB. Ethanol withdrawal and hyperalgesia. Curr Drug Abuse Rev 2009;2:41-50.

93. Gomez R, Behar KL, Watzl J, Weinzimer SA, Gulanski B, Sanacora G, et al. Intravenous ethanol infusion decreases human cortical $\gamma$-aminobutyric acid and $\mathrm{N}$-acetylaspartate as measured with proton magnetic resonance spectroscopy at 4 tesla. Biol Psychiatry 2012;71:239-46.

94. Gilman JM, Ramchandani VA, Crouss T, Hommer DW. Subjective and neural responses to intravenous alcohol in young adults with light and heavy drinking patterns. Neuropsychopharmacology 2012;37:467-77.

95. Zoethout RW, de Kam ML, Dahan A, Cohen AF, van Gerven JM. A comparison of the central nervous system effects of alcohol at pseudo-steady state in Caucasian and expatriate Japanese healthy male volunteers. Alcohol 2012;46:657-64. 